\title{
Female mate choice and mate search tactics in a sex role reversed population of the peacock blenny Salaria pavo (Risso, 1810)
}

\author{
T. Fagundes*, D. M. Gonçalves and R. F. Oliveira \\ Unidade de Investigação em Eco-Etologia, Instituto Superior de Psicologia \\ Aplicada, Rua Jardim do Tabaco, 34, 1149-041 Lisboa, Portugal
}

(Received 19 December 2005, Accepted 2 February 2007)

\begin{abstract}
Behavioural observations were carried out on a sex role reversed population of the blenny Salaria pavo to investigate possible mate choice behaviour of the females. Females mated with relatively larger males, with a larger head crest, anal gland and genital papilla, which had more eggs in their nests and that courted the female. Thus, these male traits were potentially assessed by females when choosing their mates. In order to mate, females visited one to four males (eight females spawned with the first male they had visited and eight visited more than one male). The majority of the females spawned with the last male visited but three of them returned to mate with males visited previously (two with the penultimate visited male). Additionally, the outcome of the first visit of each female depended on the quality of the males: males that were accepted on this first visit had larger head crest than rejected males. Therefore, the mate searching model that best fitted the data was a threshold tactic that allowed the searching individual to return to any potential mate visited before, i.e. that allowed for complete recall. Moreover, three females returned to mate with males rejected earlier during the search, which indicates that they lowered their thresholds. These results suggest that females use a 'one step decision' tactic to search for mates. In this tactic, females mate with males that satisfy an adjustable threshold criterion, balancing the quality of the mates expected to find in the next step of the search and the effort of finding them.

(C) 2007 The Authors

Journal compilation $(2007$ The Fisheries Society of the British Isles
\end{abstract}

Key words: Blenniidae; inter-sexual selection; mate search; 'one step decision'; 'sequential search'; sex role reversal.

\section{INTRODUCTION}

Mate choice is favoured when the benefits of choosing mates exceed the costs of being choosy. The benefits of mate choice have always been central to sexual selection theory (Darwin, 1871; Fisher, 1915; Trivers, 1972; Williams, 1975; Zahavi, 1975; Hamilton \& Zuk, 1982; Heywood, 1989; Hoelzer, 1989). Contrary to selectivity benefits, choosiness costs have been largely overlooked. These costs

*Author to whom correspondence should be addressed. Tel.: +351 218811700; fax: +351 218860954; email: tfagundes@ispa.pt 
can be related to mate sampling tactics and involve time and energy costs, increased risk of predation, risk of being attacked when entering the male's territories, or risk of losing a potential mate to a competitor while sampling mates (Daly, 1978; Parker, 1983; Real, 1990). The extent of such costs, amongst others, depends importantly on environmental characteristics, distribution of potential mates and time constraints. Empirical studies on mate searching (Trail \& Adams, 1989; Choudhury \& Black, 1993; Rintamäki et al., 1995; Dale \& Slagsvold, 1996; Gibson, 1996; Uy et al., 2001) were the logical consequence of several theoretical models proposed in the 1980s, but very few of them were carried out on fishes (Gronell, 1989; Milinski \& Bakker, 1992; Forsgren, 1997).

Several theoretical models of mate search tactics have been proposed. In the most simple model, the 'random mating' model, there is no active choice of mates and thus individuals mate randomly. In the 'fixed threshold' model (Janetos, 1980; Wittenberger, 1983) individuals mate with the first potential mate they visit that exceeds a minimum threshold of some quality. Therefore, the search ends when that individual is found and the chosen mate is always the last of the sampling sequence while the number of individuals sampled may vary. The 'one step decision' model (Janetos, 1980; called 'sequential mate choice' by Real, 1990) is similar to the 'fixed threshold' model but the threshold is not fixed. In this model, the individual balances the quality of the mates expected to be found in the next step of the search and the effort of finding them. As in the former model the number of individuals sampled is variable. According to the definition of Janetos (1980), the chosen mate is the last visited individual, but Real (1990) considers the possibility of recall, or in other words the possibility that the searching individual is able to find a potential mate again after having visited others. The 'sequential comparison' model (Wittenberger, 1983) is a sequential sampling tactic that stops when the quality of the potential mates visited starts to decrease. At this point the searcher 'decides' whether to mate with the individual last visited or the one before it, balancing the difference in quality between the two and the costs of returning to the second last. A variable number of potential mates is visited and the chosen mate is either the last or the second last individual sampled. Finally, in the 'best of n' model (Janetos, 1980; Wittenberger, 1983; Real, 1990), also named the 'pool comparison' tactic, complete recall is assumed. In this model, a fixed number of potential mates are sampled, or the search has a fixed duration or searching distance before the best of the potential mates sampled is chosen. The choice of the mate in this model is independent of the visiting order of the females' sampling sequence.

Real (1990) stressed that different degrees of selectivity are to be expected in different searching individuals, depending on the searchers' perception of the distribution of the quality of potential mates in the population, and on the costs associated with the search. This variation in the selectivity of the searchers leads to variation in the threshold level for mate acceptance, or in the number of potential mates sampled (Real, 1990). As a consequence, the quality of mates accepted and the number of males visited may not be sufficient to distinguish which tactic the searchers use. Moreover, when assuming the occurrence of complete recall, information about the order in the sampling sequence in which the mate was visited before being accepted may also not suffice to 
identify the actual mate searching tactic. Having realized that, Real (1990) proposed that an additional difference between the 'best of n' and the 'one step decision' tactic would be the quality of potential mates rejected or accepted in the first visits the searcher makes. This is so because the optimal behaviour in the 'best of n' model is to sample a certain number of potential mates and only then decide which one to choose; whereas in the 'one step decision' model the searcher mates as soon as it finds a potential mate that exceeds an adjustable threshold. Therefore, the rejection or acceptance of the first individuals visited depends on their quality, when the latter model is followed, while, it is independent of the potential mate qualities (i.e. it depends only on the selectivity of the searcher, reflected in the number of individuals sampled before mating) when the 'best of n' model is followed.

In this study, female mate choice criteria and searching behaviour were analysed in a sex role reversed population of the peacock blenny Salaria pavo (Risso, 1810). This species lives in intertidal areas in the Mediterranean Sea and adjacent North Atlantic coasts (Zander, 1986). The mating system is polygynandric and males, which are territorial and larger than females, establish their nests in rock crevices where they provide parental care for the eggs without the help of the female (Patzner et al., 1986). The population studied is situated in Ilha da Culatra, a sand barrier island located off a coastal lagoon in Ria Formosa (southern Portugal). There, due to the lack of rocky substratum, males use holes in debris, mainly bricks, as nests and since these are scarce and agglomerated there is a strong competition among males for the access to nesting sites (Almada et al., 1994, 1995; Oliveira et al., 1999). The probability of nest take-overs by other males is thus high and males seldom leave their nests. Consequently, in this population the breeding territories are restricted to the nest itself (Almada et al., 1994) and male courtship behaviour is rare (Almada et al., 1995). Another consequence of nest limitation is a shortage of the number of males that can reproduce, probably resulting in a female biased operational sex ratio. The limited space inside the nests, which at the peak of the breeding season may be saturated with eggs (Almada et al., 1995; Oliveira et al., 1999), intensifies this bias and renders the males the limiting reproductive factor. These conditions seem to be the cause of the observed sex role reversal, where males are very selective, rejecting a high proportion of the females and females are the sex that courts more actively and that initiates most of the courtship episodes (Almada et al., 1995).

In spite of the reversed sex roles in courtship behaviour, males exhibit the most developed secondary sex traits during the reproductive season: an anal gland in the first two rays of the anal fin and a conspicuous head crest (Fishelson, 1963; Patzner et al., 1986; Patzner \& Seiwald, 1987). Although Oliveira et al. (1999) and Gonçalves et al. (2002a) found no correlation between head crest size and reproductive success, other studies show a positive correlation between reproductive success and body length, anal gland size (Oliveira et al., 1999) or head crest size (E. Barata, unpubl. data), which suggests that these traits might be under sexual selection. This study focused on inter-sexual selection and its goals were to determine: (1) whether females select mates and, if so, which characteristics are used to assess male quality and (2) how do females search for males and which tactics are they using to sample them. 


\section{MATERIALS AND METHODS}

This study was conducted during the peak of the breeding season of this population, from the third week of May until the end of July 2000 at Ilha da Culatra (Ria Formosa, southern Portugal). A $35 \mathrm{~m}$ long transect, composed of 40 bricks was monitored throughout the study. Every 2 weeks, all exposed bricks were inspected during low tide, and the individuals' location and biometrical variables were recorded. Standard length $\left(L_{\mathrm{S}}\right)$ was registered to the nearest $\mathrm{mm}$ and an ordinal scale ranging from 0 (not developed) to 9 (fully developed) was used to score the height of the head crest and the size of the anal gland and of the genital papilla. The percentage of the nest that was covered with eggs was registered frequently for all the nests (checked on average $2 \cdot 1$ days before the visits of the females, and never more than 8 days before) and the number of eggs estimated (Gonçalves et al., 2002a). Fish were captured individually by gently shaking them out of the bricks. Fish were tagged with a combination of coloured beads attached to a fishing line (diameter $=0.3 \mathrm{~mm}$ ) inserted at the base of the dorsal fin for individual identification, following the procedure described by Patzner \& Seiwald (1984). To minimize stress, fish were lightly anaesthetized with MS-222 (tricaine methanesulphonate) before manipulation. After measurements fish were recovered in a container with abundant water and aeration, and returned to the brick from which they were captured. No mortality due to manipulation or anaesthesia occurred.

Females used in field observations were captured during low tide from exposed bricks or other debris and transported to a field station located at the island. To ensure that females had no prior knowledge of the males to which they were being presented, females were caught on different parts of the island, some distance from the transect where the field observations were to be carried out. Females were anaesthetized, measured and tagged as described above. Additionally, to standardize their motivation to spawn, they were injected, in the peritoneal cavity, with $150 \mu \mathrm{l}$ of a solution of a gonadotropin analogue (des-Gly ${ }^{10},\left[\mathrm{~d}-\mathrm{Ala}^{6}\right]$-luteinizing hormone releasing hormone ethylamide, Sigma), at a concentration of $2.5 \mu \mathrm{g}$ per $100 \mu \mathrm{l}$. Females were maintained for $48 \mathrm{~h}$, the time expected for the hormone to be most effective (A. V. M. Canário \& R. F. Oliveira, unpubl. data) in a 1151 aquarium without any males. The aquarium reproduced the natural conditions of the population habitat (sandy substratum with shelters, temperature $=20^{\circ} \mathrm{C}$, range $\pm 2^{\circ} \mathrm{C}$ and 16L:8D cycle). Females were fed daily with chopped common cockles. To confirm their breeding motivation, they were presented to a nesting male, prior to their release. Only females that courted the 'stimulus' male in the pre-test were subsequently used in the field observations. A total of 39 females were released in the transect, one at a time. No more than four females were released during each day and most abandoned the transect soon after their release $(87 \%$ in $<5$ days; recapture or sighting rate $=16 \%)$. Hence no inflation of the number of females on the transect was observed throughout the study. Before being released, females were placed in a glass box (16 l) in a random location of the transect for $5 \mathrm{~min}$ before the start of the observations in order to acclimate to the new conditions. Continuous focal observations of $60 \mathrm{~min}$ (Martin \& Bateson, 1993), with a time resolution of $30 \mathrm{~s}$, were conducted by following females while snorkelling. The number and duration of courtship displays of the focal female and of the males they approached were registered (durations registered with a time resolution of $1 \mathrm{~s}$ ) on an underwater slate. The location of the female was also recorded to calculate the total swimming distance.

Binomial and $\chi^{2}$ tests (Statistix, version 1.0, from Analytical Software) were used to analyse the frequencies of behaviours. The two-tailed significance level used to reject the null hypotheses was 0.05.

\section{FEMALE PREFERENCE FOR MALE TRAITS}

To test which male traits could potentially be assessed by females, males that were visited by females and that defended a nest were divided in two groups, 'accepted males' and 'rejected males'. A visited male was defined as a male that received courtship displays and spawns from females, since these were the only unambiguous criteria to define a visit. 
Spawns are not possible to observe as they take place inside nests, thus a uniform criterion was used to define spawning. Using only the criterion of a female entering a nest was not sufficient for defining spawning because some females left the nests immediately after they had entered. Therefore, $300 \mathrm{~s}$ was set to be the necessary minimum time for a female to spawn after entering a nest [as defined by Neat et al. (2003) for the sister species Salaria fluviatilis (Asso, 1801)]. 'Accepted males' were defined as those that received at least one spawn from a female and 'rejected males' those that never mated. Floater males were excluded from the analyses. These males usually swim around the transect area and have no established nests, for this reason, they may not have the necessary conditions to mate, due to intra-sexual rather than inter-sexual selection. The behavioural and morphological variables measured in these two groups of males (i.e. 'accepted' $v$. 'rejected') were compared. The number of eggs present in the nests before the focal observations was also compared. Since many males were visited by more than one female, the behavioural and morphological variables presented by each male during the different observations were averaged. In this way there were no repeated male subjects in the statistical analysis. Moreover, some 'accepted males', although accepted by some, were rejected by other females. In these cases, the averages calculated included only the observations where these 'accepted males' were in fact accepted, i.e. where they did mate. Thus, data about the same 'accepted' males obtained during the observations where they did not mate were excluded from the analysis. In this study, only one female spawned more than once during the focal observations. Data obtained from both the searching sequences of this female, that spawned twice, were included in the analysis and this was the only source of non-independent data. As data did not conform to the assumptions of parametric procedures Mann-Whitney $U$-tests (SPSS 14.0 for Windows) were applied throughout. Tests were two-tailed and null hypotheses were rejected at probabilities of type I error $<0.05$.

Besides the fact that males included in the analysis had an established nest, they should have had space in their nests to receive spawning from females. Only if these two conditions were met were males considered to be available for mating. The available nest space of the males observed was checked to verify this latter condition. The males had a mean \pm S.E. $36 \cdot 6 \pm 3 \cdot 6 \%$ of the internal area of the nest covered with eggs. Ninety five per cent of the males in the analysis had $<80 \%$ of eggs, so they were able to receive new eggs from visiting females. Two males had 90 and $98 \%$ of the nests covered with eggs but 63 and $59 \%$ of the nests area had eggs ready to hatch (within 3 days). Since these measurements were taken 3-4 days, respectively, before the visit of the focal females, it was assumed that by time the female visited these males, their nests would have available space to receive more eggs.

\section{MATE SEARCHING TACTIC}

The visiting sequences of the females were analysed and compared to the distinctive features of each of the mate search models described in the introduction, namely the number of males visited and the order of the accepted males in the sequence of the females' visits. The traits of the males that were accepted during the first visits of the females were compared to traits of rejected males in those first visits, to evaluate if the probability of a male being accepted at first was independent or not of its quality. Because some females visited the same males first in their sampling sequence, data from these males were repeated. The data from each of the repeated male inside each of the groups compared (accepted and rejected males in the first visits of the females) was averaged and the three males that were still included in both groups were randomly excluded from one of them. One-tailed, Mann-Whitney $U$-tests (SPSS 14.0 for Windows) were applied to these data with a significant level 0.05. The use of one-tailed tests is justified by the theoretical hypothesis tested: $H_{0}$ : no differences between the quality of males accepted and rejected in the firsts visit of each of the females (which would support the 'best of n' tactic) against $H_{1}$ : accepted males are higher quality males then the rejected ones (which would support a threshold tactic and oppose the 'best of n' tactic). 


\section{RESULTS}

\section{GENERAL RESULTS}

Of the 39 focal females released in the transect, 15 spawned. Four females did not spawn although they courted males, and 20 were not active or presented some other kind of non-sexual activity, usually foraging. The latter were excluded from further analyses. Of the females that spawned, only one did so twice during the same observation. Out of the 54 courtship interactions observed, 14 were initiated by male courtship displays and 39 by female sexual displays [binomial test $(14,53,0.5), P<0.001]$. In one case, mating occurred without any of the individuals involved courting the other one. The occurrence of spawning was independent of whether females, males or both displayed courtship behaviour (exclusive male courtship: two with spawn, 18 without spawn; exclusive female courtship: four with spawn, 15 without spawn; mutual courtship: nine with spawn, 13 without spawn; $\chi^{2}$, d.f. $=2, P>$ $0 \cdot 05)$. From the 42 courtship episodes in which males courted the females, $31(74 \%)$ were not followed by spawning and six of the 10 females that sampled more than one male, received courtship displays from males that they did not mate with.

\section{FEMALE PREFERENCE FOR MALE TRAITS}

'Accepted males' were larger [Fig. 1(a)], and had more developed sexual characters: larger head crests [Fig. 1(b)], larger anal glands [Fig. 1(c)] and larger genital papillae [Fig. 1(d)] than 'rejected males'. Accepted males had more eggs in their nests [Fig. 1(e)] relatively to 'rejected males' and displayed courtship behaviour [Fig. 1(f)] while most of the 'rejected males' did not.

\section{FEMALE MATE SEARCHING TACTIC}

The duration and extent of the searching sequences were variable (mean \pm S.E. duration: $1283 \pm 252 \mathrm{~s}, n=16$; path length: $2 \cdot 15 \pm 0.48 \mathrm{~m}, n=16$ ). Females visited one to four males before they spawned (mean \pm s.E. $=1.75 \pm$ $0 \cdot 25, n=16$ ). Eight females mated with the first visited male, six visited two males before mating (one of these was actually the second searching sequence of the female that spawned twice) and two visited four males until they spawned. In 13 of the 16 sampling sequences (15 females), the females mated with the last male visited. In eight out of these 13 sequences, females mated with the first, and only, male visited. Three females returned to previously courted males, having meanwhile courted others. Two of these females, returned to the second last male visited and in both these cases the second last and the last males visited had adjacent nests in the same face of the same brick. The other female returned to spawn in the nest of a male visited in the beginning of the searching sequence, having to swim back from nearby bricks.

Considering only the first males that each female visited during the focal observations, the males that did not mate in these first visits had smaller head 

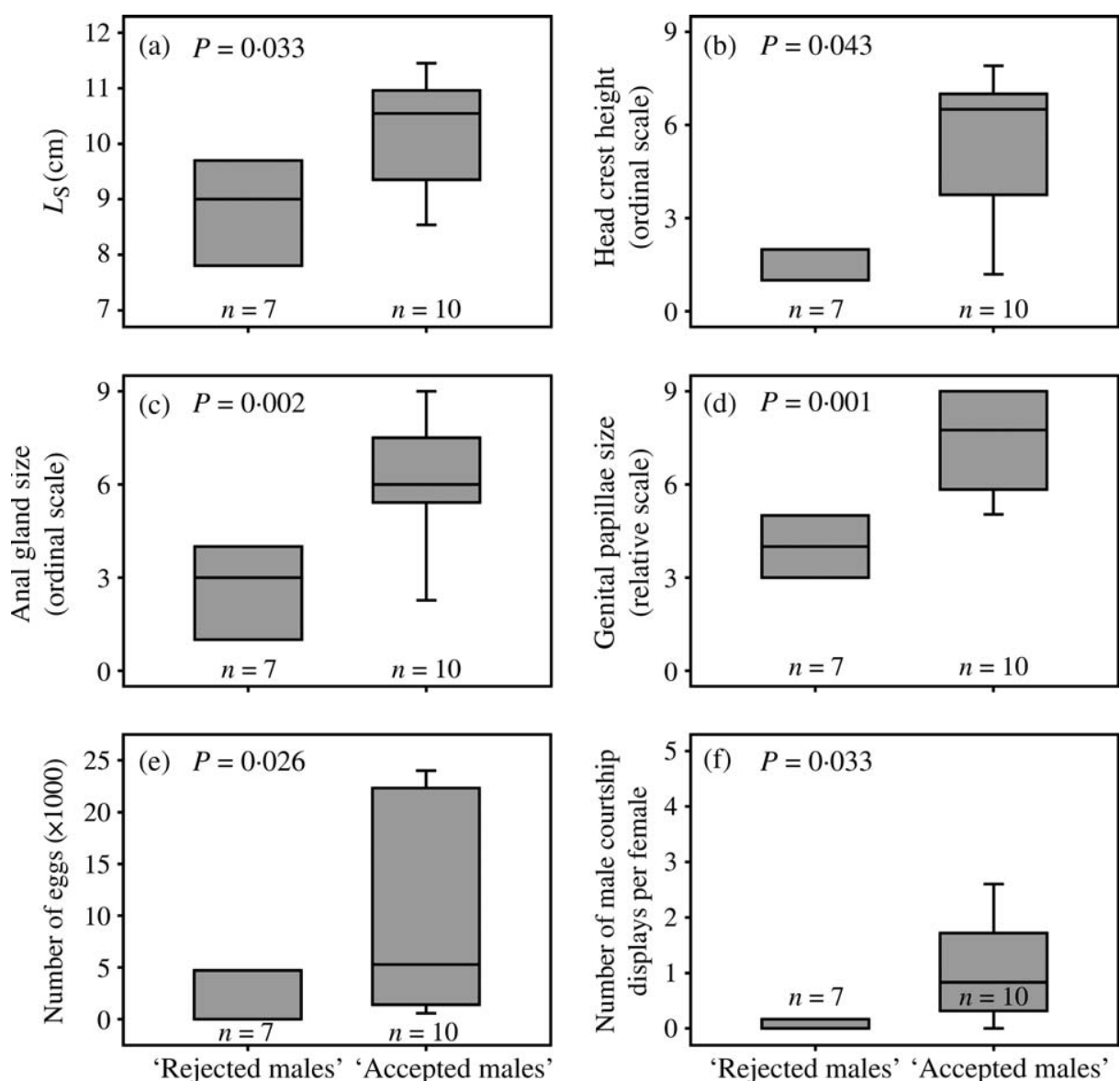

FIG. 1. Boxplots (box: median with quartiles; whiskers: 5 and $95 \%$ boundaries; $P$-values are results of two-tailed Mann-Whitney $U$-tests) of different male traits of Salaria pavo (a) standard length, (b) head crest height, (c) anal gland size, (d) genital papillae, (e) number of eggs and (f) number of male courtship displays per female. 'Rejected males' are the males that did not mate with the focal females, 'accepted males' are those that mated, at least once, with the focal females.

crests than the ones that mated [Fig. 2(b)]. The other male traits measured, with the exception of $L_{\mathrm{S}}$, showed the same tendency as the head crest, although differences were not significant (Fig. 2).

Two focal observations, in particular, deserve more attention. The females (A and $\mathrm{B})$ in these observations visited first a large male $(\hat{\jmath} \mathrm{A} 1=10.9 \mathrm{~cm}$

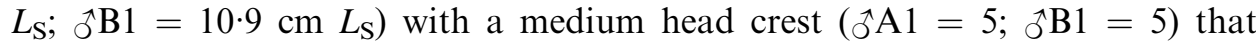
had plenty of eggs in the nest $\left(\hat{\mathrm{A}} \mathrm{A}=21600\right.$ eggs; $\left.{ }^{\wedge} \mathrm{B} 1=21600 \mathrm{eggs}\right)$ and that courted the females once. The second visited males were smaller ( $\hat{A} \mathrm{~A} 2$ $\left.=9.0 \mathrm{~cm} L_{\mathrm{S}} ; \jmath^{1} \mathrm{~B} 2=9.6 \mathrm{~cm} L_{\mathrm{S}}\right)$, with less developed head crests $(\hat{\mathrm{A}} \mathrm{A} 2=2$; ${ }^{1} \mathrm{~B} 2=1$ ), were not guarding eggs and they did not court the females. Both females returned to spawn with the first male they visited and this time males did not court females. 

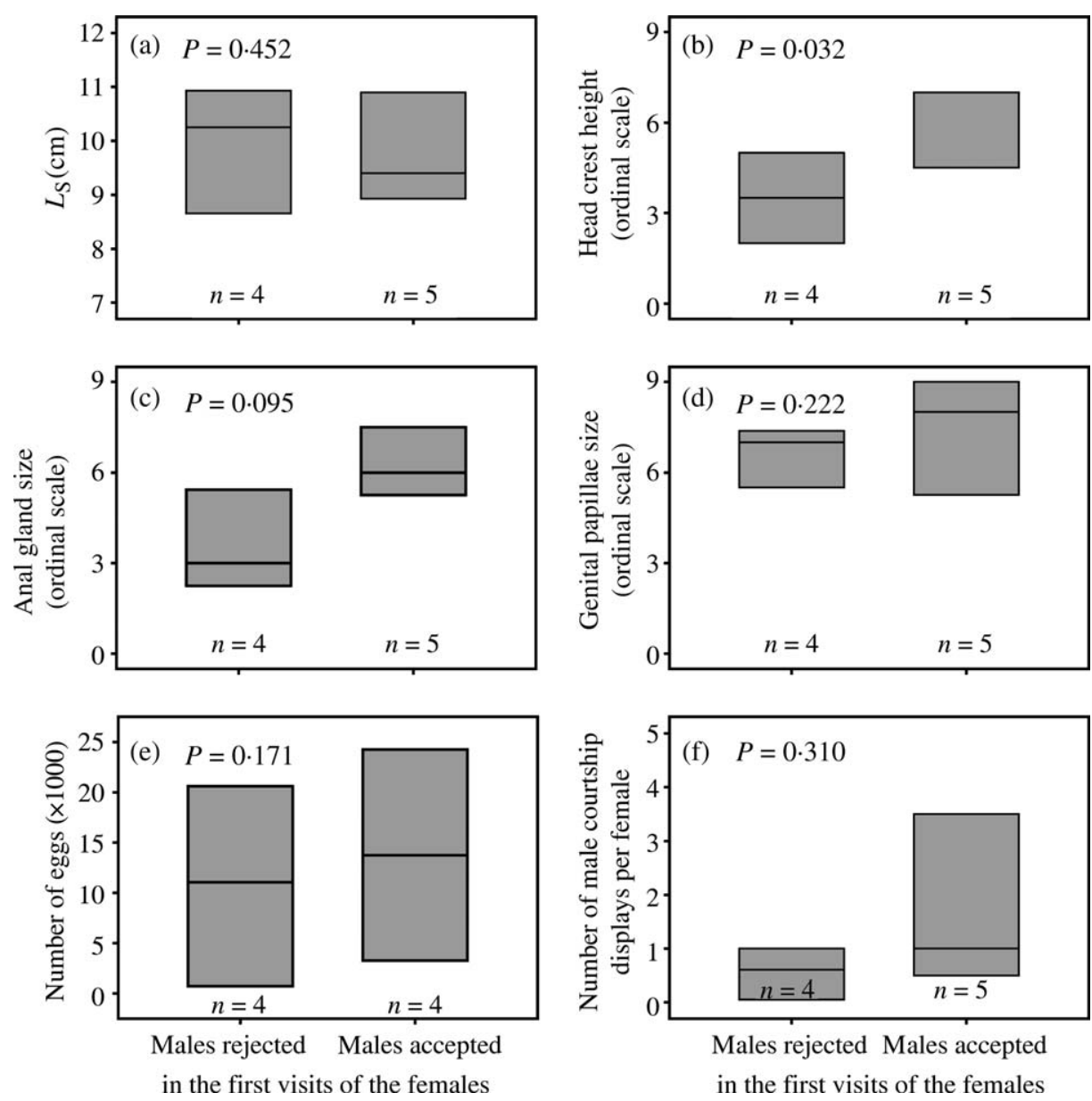

FIG. 2. Boxplots (box: median with quartiles; whiskers: 5 and $95 \%$ boundaries; $P$-value is the one-tailed result of Mann-Whitney $U$-test) of male traits of Salaria pavo (a) standard length, (b) head crest height, (c) anal gland size, (d) genital papillae, (e) number of eggs and (f) number of male courtship displays per female. Accepted males are males that received spawnings from females during the first visit these females paid to males. Rejected males did not mate with the females that visited them first.

\section{DISCUSSION}

\section{MALE TRAITS PREFERRED BY FEMALES}

Females of $S$. pavo mated with the relatively larger males of the transect, and that had relatively larger head crests, anal glands and genital papillae. They spawned with males that courted them and that had relatively high numbers of eggs in their nests. The preference for males found with these traits suggests that these traits are potentially assessed during mate choice.

Males are very selective in the studied population (Almada et al., 1995) which complicates the analysis of female choice, even more so, because courtship displayed, either by males or by females, is not strictly associated with the 
acceptance of the potential mate. Yet, the pattern of preferences found attests the existence of female choice. In the present study, all the males analysed were able to reproduce, they were all defending nests and all except two had been parental males during the same breeding season. Moreover, they were in conditions to receive more eggs in their nests. Therefore, the clear differences found between 'accepted' and 'rejected' males cannot be explained by the lack of reproductive abilities of some males. Additionally, some of the earlier studies have shown that larger males and males with larger secondary sexual characters (Oliveira et al., 1999; E. Barata, unpubl. data) have higher reproductive success. Being so, it would be expected that these males would have higher potential for being selective towards females. In such a situation, male selectivity alone would not have explained the results obtained. The 'rejected males' of this study, those that never mated would be interpreted as the most selective, having rejected all focal females that visited them, and would be expected to have larger secondary sexual characters and body size. Yet, the results of these study show the 'rejected males' (i.e. males that would be interpreted as more selective) to be smaller males and have less developed secondary sexual characters than the males classified as 'accepted males' (i.e. males that would be interpreted as the less selective since they have accepted some of the focal females). Therefore, the differences between 'accepted' and 'rejected' males can also not be explained by male selectivity.

Finally, $73 \%$ of the courtship episodes in which males courted the females were not followed by spawning, and $60 \%$ of the females that sampled more than one male did not mate with some males that courted them, which indicates that these females were not rejected by the males. Therefore it can be concluded that, despite the selectivity of the males, the observed patterns strongly suggest the existence of female choice in this population.

The results presented here are in agreement with previously reported higher reproductive success of larger males in this population (Oliveira et al., 1999; Gonçalves et al., 2002a). Although intra-sexual competition is expected to be the strongest driving force of this higher success due to male-male competition for the access to nests. The present study also is consistent with laboratory controlled studies that have shown that males with larger head crests receive more eggs (E. Barata, unpubl. data) and more courtship displays from females (Gonçalves et al., 2002b) and that females spend more time close to males with larger crests (Gonçalves \& Oliveira, 2003). In spite of all these studies showing the same trend, choice tests that control for the correlations between male traits are needed in order to disentangle which male traits are effectively assessed.

\section{FEMALE MATE SEARCHING TACTIC}

In this study, the head crest of the males accepted in the first visits of the females was larger than the head crest of those rejected. This result supports a threshold tactic while opposing the comparative tactics: the 'best of n' and the 'sequential comparison' of Wittenberger (1983). The mate searching models that are based on thresholds, as the 'fixed threshold' and the 'one step decision' 
models predict the comparison of the males' characteristics to a threshold of quality that can be fixed or adjustable. Different females are expected to use different levels of threshold, depending on their perception of the distribution of the quality of males in the population and of the cost of the search (Real, 1990). Furthermore, whenever females are also subjected to male mate choice, as it is the case in this population, the qualities of the searching females that will influence their probabilities of being accepted by the males, should also influence the definition of the threshold. Hence, a definite level of threshold of mate acceptance shared by all the females is not likely to be found (Real, 1990). The comparative methods, on the other hand, assume the sampling of a group of males and the comparison of the qualities they possess. For the 'best of n' tactic, a female should sample an optimal number of males independently of the quality of the males she finds as the search goes on. This optimal number of males is also expected to vary between females, again depending on the perception of the distribution of the quality of males, of the costs of the search and other factors. Consequently, the number of males sampled is not enough to identify the mate-searching tactic (Real, 1990). Moreover, when considering Real's (1990) perspective of the 'one step decision' tactic which does not preclude complete recall, the order in which the mated males were visited in the sampling sequence is an insufficient criterion to distinguish between tactics as well. Real (1990) predicts, though, that females that use the 'best of n' tactic should sample the optimal number of males irrespectively of the quality of the males they find. In this case, as in the 'sequential comparison' of Wittenberger (1983), the probability that a male is accepted at the first visit a female makes, depends on the selectivity of the female and not on the quality of the male encountered. This implies that males accepted and males rejected in the first visit should not differ. The threshold tactics on the other hand are expected to reveal a difference between males accepted and rejected in the first female visits, as the choice of a male is dependent on its quality and not on the comparison with other males. Females of $S$. pavo did accept males with larger head crests in their first visits and rejected those with smaller crests, which supports the use of a threshold tactic by these females.

Additionally, in concordance with the hypothesis of a threshold tactic, is also the fact that the number of males sampled, the time and the duration of the search varied between females and that most of the females spawned with the last male visited, although these are not distinctive features of the different tactics. And, when considering the possibility of recall, as Real (1990) did, the fact that two females spawned with the penultimate visited males and one of them returned to a male visited in the beginning of the search, is not incompatible with the assumptions of this class of tactics.

Finally, assuming that all females use the same searching tactic in the population, the analysis of the searching sequences of the two females that returned to the penultimate visited male, described in the results, excludes the hypothesis of a 'fixed threshold' tactic, since in order to accept the male rejected in the beginning of the search, the females had to lower their threshold of acceptance.

The mate tactic that is closest to this description is the 'one step decision' tactic in case complete recall is admitted. Because females belong to this 
population and they were caught in the wild, they are presumed to have a perception of the distribution of the males' quality. For this reason, they may have already established some threshold that would allow them to accept a good male even if that was the first male encountered. On the other hand, because the 'one step decision' tactic is a tactic of adjustable threshold, females can adjust the more precise notion of the distribution of males quality and of the costs of search they might achieve during the search and, for instance, lower their threshold if male quality was overestimated or costs of the search underestimated. This decrease in the threshold level would justify the fact that females sometimes return back to mate with a male initially rejected.

According to Real (1990), the 'one step decision' tactic is more effective than the 'best of n' tactic when the costs of search are considered and the difference in performance between this two tactics is maximal when the intensity of the costs is not extremely high or extremely low. Peacock blenny females do have time constraints, because they have a limited breeding season and also because spawning can only be carried out during high tide, when nests are submerged. Searching for a mate also has costs for these females since predations by eels Anguilla anguilla (L., 1758) and marine birds such as the little egret Egretta garzetta were observed (unpubl. obs.). Costs related to female-female competition over mates are expected to be high in this population due to the promiscuous mating system and to the hypothesized limiting reproductive rate of males.

In summary, these results provide evidence for female mate choice in this sex role reversed population and suggest some male traits that might be used by females to assess male quality, namely: male's body size, development of the anal gland, genital papillae and, in particular, head crest, male courtship frequency and the number of eggs brooded by the male. The results indicate that females use the 'one step decision' tactic, theoretically considered the optimal mate searching tactic when medium searching costs are expected.

The authors want to thank R. J. Matos, L. A. Carneiro, S. Matos, Al. Ros for field assistance and all the help provided. The direction of the Parque Natural da Ria Formosa and the Universidade do Algarve provided essential technical and logistical support. This study is part of a larger research grant awarded to R.F.O. (FCT/PNAT/BIA/ $15090 / 99-C)$. R.F.O. research is supported by a plurianual programme fund from Fundação para a Ciência e Tecnologia (RI \& D unit 331/94), D.M.G. was supported by a PhD fellowship from FCT (PRAXIS XXI/BD/13436/97). T.F. was supported by a student fellowship (PRODEP-medida 3-acção 3.2).

\section{References}

Almada, V. C., Gonçalves, E. J., Santos, V. \& Baptista, C. (1994). Breeding ecology and nest aggregations in a population of Salaria pavo (Pisces: Blenniidae) in an area where nest sites are very scarce. Journal of Fish Biology 45, 819-830.

Almada, V. C., Gonçalves, E. J., Oliveira, R. F. \& Santos, A. J. (1995). Courting females: ecological constraints affect sex roles in a natural population of the blenniid fish Salaria pavo. Animal Behaviour 49, 1125-1127.

Choudhury, S. \& Black, J. M. (1993). Mate-selection behaviour and sampling strategies in geese. Animal Behaviour 46, 747-757. 
Dale, S. \& Slagsvold, T. (1996). Mate choice on multiple cues decisions rules and sampling strategies in female pied flycatchers. Behaviour 133, 903-944.

Daly, M. (1978). The cost of mating. American Naturalist 112, 771-774.

Darwin, C. (1871). The Descent of Man, and Selection in Relation to Sex. London: Murray.

Fishelson, L. (1963). Observations on littoral fishes of Israel. I. Behaviour of Blennius pavo Risso (Teleostei: Blenniidae). Israel Journal of Zoology 12, 67-80.

Fisher, R. A. (1915). The evolution of sexual preferences. Eugenics Review 7, 184-192.

Forsgren, E. (1997). Mate sampling in a population of sand gobies. Animal Behaviour 53, 267-276.

Gibson, R. M. (1996). Female choice in sage grouse: the roles of attraction and active comparison. Behavioural Ecology and Sociobiology 39, 55-59.

Gonçalves, D. M. \& Oliveira, R. F. (2003). Time spent close to a sexual partner as a measure of female preference in the sex-role reversed blenny Salaria pavo (Risso). Acta Ethologica 6, 1-5.

Gonçalves, D. M., Simões, P. C., Chumbinho, A. C., Correia, M. J., Fagundes, T. \& Oliveira, R. F. (2002a). Fluctuating asymmetries and reproductive success in the peacock blenny. Journal of Fish Biology 60, 810-820.

Gonçalves, D. M., Barata, E. N., Oliveira, R. F. \& Canário, A. V. M. (2002b). The role of male visual and chemical cues on the activation of female courtship behaviour in the sex-role reversed peacock blenny. Journal of Fish Biology 61, 96-105.

Gronell, A. M. (1989). Visiting behaviour by females of the sexually dichromatic damselfish Chrysiptera cyanea (Teleostei: Pomacentridae): a probable method of assessing male quality. Ethology 8, 89-122.

Hamilton, W. D. \& Zuk, M. (1982). Heritable true fitness in birds: a role for parasites? Science 218, 384-386.

Heywood, J. S. (1989). Sexual selection by the handicap mechanism. Evolution 43, 13871397.

Hoelzer, G. A. (1989). The good parent process of sexual selection. Animal Behaviour 38, 1067-1078.

Janetos, A. C. (1980). Strategies of female choice: a theoretical analysis. Behavioural Ecology and Sociobiology 7, 107-112.

Martin, P. \& Bateson, P. (1993). Measuring Behaviour. An Introductory Guide, 2nd edn. Cambridge: Cambridge University Press.

Milinski, M. \& Bakker, T. (1992). Costs influence sequential mate choice in sticklebacks Gasterosteus aculeatus. Proceedings of the Royal Society of London B 250, 229-233.

Neat, F., Lemkeek, W., Westbeek, E. P., Laarhoven, B. \& Videler, J. J. (2003). Behavioural and morphological differences between lake and river populations of Salaria fluviatilis. Journal of Fish Biology 63, 374-387.

Oliveira, R. F., Almada, V. C., Forsgren, E. \& Gonçalves, E. J. (1999). Temporal variation in male traits nesting aggregations and mating success in the peacock blenny. Journal of Fish Biology 54, 499-512.

Parker, G. A. (1983). Mate quality and mating decisions. In Mate Choice (Bateson, P., ed.), pp. 141-166. Cambridge: Cambridge University Press.

Patzner, R. A. \& Seiwald, M. (1984). Individual tagging of small fish. Aquaculture 40, $251-253$.

Patzner, R. A. \& Seiwald, M. (1987). The reproduction of Blennius pavo. VII. Secondary sexual organs and accessory glands of the testis during the reproductive cycle. In Proceedings of the V Congress of European Ichthyologists (Kullander, S. \& Fernholm, B., eds), pp. 293-298. Stockholm: Swedish Museum of Natural History.

Patzner, R. A., Seiwald, M., Adlgasser, M. \& Kaurin, G. (1986). The reproduction of Blennius pavo. Zoologischer Anzeiger 216, 338-350.

Real, L. (1990). Search theory and mate choice. I. Models of single-sex discrimination. American Naturalist 136, 376-404.

Rintamäki, P. T., Atalo, R. V., Höglund, J. \& Lundberg, A. (1995). Mate sampling behaviour of black grouse females (Tetrao tetrix). Behavioral Ecology and Sociobiology 37, 209-215. 
Trail, P. W. \& Adams, P. S. (1989). Active mate choice at cock-of-the-rock leks: tactics of sampling and comparison. Behavioral Ecology and Sociobiology 25, 283-292.

Trivers, R. L. (1972). Parental investment and sexual selection. In Sexual Selection and the Descent of Man (Campbell, B., ed.), pp. 136-179. Chicago, IL: Aldine.

Uy, J. A. C., Patricelli, G. L. \& Borgia, G. (2001). Complex mate searching in the satin bowerbird Ptilonorhynchus violaceus. American Naturalist 158, 530-542.

Williams, G. C. (1975). Sex and Evolution. Princeton, NJ: Princeton University Press.

Wittenberger, J. F. (1983). Tactics of mate choice. In Mate Choice (Bateson, P., ed.), pp. 433-447. Cambridge: Cambridge University Press.

Zander, C. D. (1986). Blenniidae. In Fishes of the North-eastern Atlantic and the Mediterranean, Vol. 3 (Whitehead, P. J. P., Bauchot, M.-L., Hureau, J.-C., Nielsen, J. \& Tortonese, E., eds), pp. 1096-1112. Paris: UNESCO.

Zahavi, A. (1975). Mate selection - a selection for a handicap. Journal of Theoretical Biology 53, 205-214. 